\title{
Práticas de risco de usuários em unidades produtoras de refeições tipo self-service na cidade do Rio de Janeiro
}

\author{
Users' risk practices in food service units in Rio de Janeiro City
}

Roseane Moreira Sampaio Barbosa'

Beatriz Bruninise de Lima e Silva Carbone ${ }^{2}$

Haydée Serrão Lanzillotti ${ }^{3}$

' Faculdade de Nutrição Emília de Jesus Ferreiro, Departamento de Nutrição Social. Universidade Federal Fluminense. Niterói, RJ, Brasil

${ }^{2}$ Faculdade de Nutrição, Universidade Gama Filho. Rio de Janeiro, RJ, Brasil

${ }^{3}$ Instituto de Nutrição, Departamento de Nutrição Social. Universidade do Estado do Rio de Janeiro. Rio de Janeiro, RJ, Brasil

Correspondência / Correspondence Roseane Moreira Sampaio Barbosa E-mail: roseanesampaio@ig.com.br

\section{Resumo}

Objetivo: Avaliar práticas de risco de usuários durante o atendimento das refeições em unidades produtoras de refeições. Método: A pesquisa foi realizada pela observação de práticas dos usuários em unidades produtoras de refeições com serviço do tipo self-service, segundo lista de checagem proposta por Zandonadi et al. (2007). Optou-se por amostra acidental. A análise dos dados constou na geração de um índice de práticas de risco, elaborando uma carta de controle tendo como ponto de corte dois desvios-padrão. O teste qui-quadrado a partir das frequências de respostas "sim" permitiu verificar a diferença entre sexos. Resultados: Comparando os perfis por sexo, verifica-se que a maior concentração de práticas de risco apareceu entre os homens, inferindo que as mulheres sejam mais cuidadosas no que se refere a atos de segurança sanitária. Conclusão: Os usuários apresentam práticas de risco para a contaminação de alimentos no ato do atendimento de refeições, sendo que em algumas situações pesquisadas o risco é bem expressivo, sobretudo entre os homens.

Palavras chave: Práticas de risco. Higiene dos alimentos. Sexo. Boas práticas de manipulação.

\section{Abstract}

Objective: To evaluate the users' risk practices during meals in food service units. Method: The survey was conducted by observing the practices of users in characteristic self-service food units, according to the checklist proposed by Zandonadi et al (2007). A random sample was chosen. Data analysis consisted 
in the generation of an index of risk practices by generating a control chart with two standard deviations cutoff. The Chi-Square test from the frequencies of "yes" showed differences between sexes. Results: Comparing the profiles by sex it seems that the highest concentration of risk practices among men appeared, implying that women are more careful with regard to health security acts. Conclusion: The users showed risk practices for food contamination during meals services, and in some situations the risk is very significant, especially among men.

Key words: Risk practices. Food hygiene. Sex. Good handling practices.

\section{Introdução}

Nas últimas décadas, a sociedade brasileira sofreu grande transformação devido ao desenvolvimento industrial. Dentre as mudanças, destacam-se os novos hábitos sociais e padrões de consumo alimentar. ${ }^{1}$ Em relação às outras dimensões, os indicadores propostos pelo $\mathrm{IBGE}^{2}$ também elegem aspectos demográficos, de educação, trabalho, desempenho macroeconômico e financeiro, habitação, segurança e dos padrões de produção e consumo. Particularmente na dimensão saúde, esforços têm sido dirigidos para a mudança do padrão do consumo e segurança alimentar e nutricional, a partir da Política Nacional de Alimentação e Nutrição e seus diferentes programas. ${ }^{3}$

Com essa transformação, o hábito de "comer fora" sofreu modificação de interpretação. Pode ser analisado o "comer fora" como atividade social e como uma necessidade imposta pelo modelo de força de trabalho no qual as mulheres passaram a ter papel relevante. ${ }^{4}$ A inclusão das mulheres no mercado de trabalho ocasionou certo distanciamento das atividades tradicionais desenvolvidas no lar; consequentemente, houve incremento na renda familiar, o que estimula a realização de refeições em restaurantes, lanchonetes, fast foods, cafeterias, etc. ${ }^{5}$

Em que pese a assertiva do autor, nem sempre a entrada da mulher no mercado de trabalho é um fator de incremento da renda, visto que há inúmeros casos em que a mulher, chefe de família, apresenta constantemente renda inferior àqueles chefiados por homens. Notícia do boletim do Dieese ${ }^{6}$ destaca que a origem dessa menor renda estaria associada ao próprio perfil da chefe de domicílio, geralmente sem cônjuge, com baixa escolaridade e idade mais avançada, bem como às dificuldades de inserção feminina no mercado de trabalho, que usualmente se expressam pela maior taxa de desemprego, inserções vulneráveis e menores rendimentos. 
No Brasil, estima-se que, de cada cinco refeições, uma é feita fora de casa; na Europa, duas em cada seis; e nos EUA, uma em cada duas. ${ }^{5}$ Esses números indicam que ainda pode haver grande aumento e desenvolvimento dos estabelecimentos que produzem alimentos para consumo imediato no país.

Segundo dados gerados em 2010 pela Associação Brasileira de Refeições Coletivas, ${ }^{7}$ o mercado de refeições coletivas como um todo fornece 9,4 milhões de refeições/dia, movimenta uma cifra de 8,6 bilhões de reais por ano. Para 2011, o potencial de produção de refeições foi estimado em 24 milhões/dia para empregados de empresas, e em 17 milhões nas escolas, hospitais e forças armadas. ${ }^{7}$ Neste cenário, a necessidade de constante aperfeiçoamento das ações de controle sanitário na área de alimentos tornou-se algo imprescindível. Regem tal necessidade de segurança alimentar as portarias $\mathrm{MS} \mathrm{n}^{\mathrm{0}} 1.428$, de 26 de novembro de 1993 (BRASIL/MS, 1993), e MS no 326, de 30 de julho de $1997,{ }^{8}$ que estabelecem as orientações necessárias para cumprimento dos requisitos necessário às "Boas Práticas de Produção e de Prestação de Serviços na Área de Alimentos". A partir da Portaria SVS/MS no 326, de $1997 .{ }^{8}$ desenvolveu-se a Resolução RDC no 275, de 21 de outubro de $2002,{ }^{9}$ que tem o propósito de atualizar a legislação geral, introduzindo o controle contínuo das Boas Práticas e os Procedimentos Operacionais Padronizados (POP). Posteriormente, a Agência Nacional de Vigilância Sanitária (ANVISA) aprovou a Resolução RDC n⿳ำ 216, de 15 de setembro de $2004,{ }^{10}$ que estabelece os procedimentos de Boas Práticas para Serviços de Alimentação.
Segundo Silva Junior, ${ }^{11}$ o controle de qualidade no serviço de alimentação é importante e abrangente, havendo necessidade de se desenvolver as técnicas operacionais com manipulação e processamento seguro para não ocorrer doenças transmissíveis por alimentos (DTA).

Um dos principais indicadores utilizados para a Segurança Alimentar e Nutricional, em relação à da garantia da qualidade biológica, sanitária, nutricional e tecnológica dos alimentos ${ }^{12}$ é a qualidade higiênicosanitária, uma vez que as DTAs são um dos principais fatores que contribuem para os índices de morbidade nos países da América Latina e do Caribe. O Comitê da Organização das Nações Unidas para Agricultura e Alimentação admite que doenças oriundas de alimentos contaminados são, provavelmente, o maior problema de saúde pública no mundo contemporâneo. ${ }^{5}$

Os principais problemas relativos à contaminação de preparações servidas em restaurantes do tipo self service são consequências do reaquecimento e refrigeração inadequados, preparação de alimentos com muita antecedência, aumentando o tempo de espera para a distribuição e atitudes de risco que podem favorecer a contaminação dos alimentos durante o atendimento em alimentação coletiva., ${ }^{5,13}$ Diferentemente dos demais autores que avaliaram as atitudes de risco em UPR, neste estudo o objeto corresponde a práticas de risco de usuários em UPR. O constructo de interesse, prática de risco, refere-se ao desrespeito a regras inerentes 
ao controle higiênico sanitário. ${ }^{11}$ As dimensões que mapeiam este constructo são ações relativas à higiene pessoal, manipulação de alimentos e consumo de alimentos no autosserviço, partindo-se das assertivas propostas pelos itens do questionário de Zandonadi et al. ${ }^{14}$

Segundo Silva Junior, ${ }^{11}$ dentre as DTAs, a mais invasiva é a toxinfecção por bactérias na forma vegetativa que liberam toxinas no trato gastrintestinal. Informações veiculadas através do DataSUS revelam que de 1999 até 2010, foram notificados pelo Ministério da Saúde,,$^{15} 6.971$ surtos, com 1.804 .932 pessoas expostas e registro de 88 óbitos. Confirmando a declaração de Silva Junior, ${ }^{11}$ o DATASUS informou que dentre das DTAs notificadas 41,1\% eram causadas por bactérias; as causas ignoradas alcançaram 51,3\%.

A Organização Mundial de Saúde (OMS) caracteriza como surto de DTA a ocorrência de dois ou mais casos que apresentem sintomas semelhantes após a ingestão de alimento ou água, de mesma origem, implicados como veículo da doença, exceto em caso de botulismo, quando uma ocorrência única já é considerada um surto. ${ }^{15}$

A partir destas informações, os gestores de Unidades Produtoras de Refeições (UPR) devem investir em uma cultura que evite atitudes de risco dos usuários. Este artigo tem objetivo de avaliar práticas de risco por usuários atendidos em uma UPR.

\section{Método}

O estudo foi conduzido em conformidade com as normas estabelecidas pelo Comitê de Ética em Pesquisa (COEP) da Universidade do Estado do Rio de Janeiro (Processo n⿳0067/2011). Trata-se de um estudo de caso, unicego, uma vez que somente os usuários não saberão que suas práticas relativas às regras inerentes ao controle higiênico sanitário estão sendo observadas. Esta estratégia é uma tentativa de evitar que os participantes do estudo saibam que aspectos serão observados. O consentimento livre e esclarecido foi solicitado ao(s) responsável(eis) das UPR.

Optou-se por amostra acidental ${ }^{16}$ com características de modelo para dados discretos, considerando o percentual de repostas positivas (70\%), uma vez que se procurou identificar práticas de risco, com nível de confiança de 95\% e precisão de $8 \%$, considerando população infinita. ${ }^{17}$ A amostra constou de no mínimo 90 usuários em cada restaurante com distribuição do tipo self service.

A pesquisa foi realizada pela observação das práticas de risco dos usuários atendidos em UPR tipo self service, de médio porte, no período de um mês. Esta empresa privada faz parte do conjunto de unidades de uma Concessionária de Refeição Coletiva localizada na cidade do Rio de Janeiro. A refeição eleita para o estudo foi o almoço dado ao maior fluxo de atendimento. 
O instrumento ainda não foi validado. Apesar de ser um estudo exploratório, Zandonadi et al. ${ }^{14}$ tiveram o cuidado de buscar sua validade de face, ${ }^{18,19}$ uma vez que os itens do questionário, que operacionalizam o construto, prática de risco, foram avaliados por juízes especialistas. Embora o autor não tenha explicitado os motivos que permitem considerar as atitudes arroladas como práticas de risco, é imperativo entender que estas foram baseadas na legislação sanitária. ${ }^{10}$

Este consta de uma lista de checagem proposta por Zandonadi et al. ${ }^{14}$ (2007), destinada a avaliar práticas de risco de usuários. Nessa lista são descritas 13 práticas de risco de mesmo sentido, a saber: a) não higienizar as mãos imediatamente antes do autosserviço; b) mexer no cabelo perto das preparações expostas no balcão; c) falar em cima das preparações no balcão de distribuição; d) deixar a gravata, a manga de camisas, bolsas, blusas, vestidos ou casacos tocarem nas preparações; e) deixar parte do corpo encostar-se às preparações; f) tossir sobre as preparações; g) espirrar sobre as preparações; h) utilizar o utensílio de uma preparação em outra já servida no prato do consumidor; i) trocar os utensílios das preparações; j) deixar o utensílio cair dentro da preparação; l) retirar o alimento do seu prato e devolvê-los às cubas com a mão ou utensílio disponível; m) consumir alimentos antes da pesagem; n) arrumar alimentos no prato com os utensílios das preparações.

O preenchimento da lista de checagem foi realizado por observação sistemática, que é o procedimento indicado em situações onde se podem estabelecer antecipadamente as atitudes sobre as quais se deseja analisar. ${ }^{16}$

A lista de checagem foi preenchida por um dos pesquisadores, atendendo aos procedimentos adequados à técnica de observação. Após a aplicação, as listas de checagem foram criticadas e conduzidas à digitação do banco de dados, em planilha Excel ${ }^{\circledR}$, utilizando-se somente as listas com todos os itens preenchidos.

A análise dos dados constou inicialmente na geração de um índice de prática de risco (relação entre o número de respostas "sim" e o total de respostas) para gerar uma carta de controle, tendo como ponto de corte dois desvios-padrão $(95,45 \%)$ e três desvios-padrão (99,73\%). Assim, foram criadas três áreas de controle estatístico de qualidade, denominadas baixo risco $(<-2 \mathrm{DP})$, médio risco (entre -2 e +2 DP) e alto risco (>+2DP). ${ }^{17}$ Quando a variação das medidas observadas (práticas de risco) é considerada inadequada (área de alto risco) e, por consequência, pode alterar a qualidade higiênico sanitária do produto, considera-se prioritário verificar suas causas para eliminá-las. Por outro lado, se a variação das medidas observadas apresenta-se na área de médio risco, entende-se ser necessário redobrar a atenção para que a preparações não se tornem impróprias para o consumo. Mesmo que a variação indique alocação em baixo risco, ainda assim são necessárias medidas corretivas, embora não prioritárias. 
O teste qui-quadrado a partir das frequências de respostas negativas permitiu verificar a diferença entre sexo. Utilizou-se o Aplicativo GraphPad Software versão 4.0. ${ }^{20}$

\section{Resultados}

Participaram do estudo 160 usuários, sendo $56,2 \%$ homens e 43,8\% mulheres. Os perfis das cartas de controle, por sexo, geradas com os índices de práticas de risco (limite superior $=$ média +2DP e limite inferior $=$ média $-2 \mathrm{DP}$ ), segundo as figuras 1 e 2 , permitiram verificar que a maior concentração de práticas de risco apareceu entre os homens. Para estes, na área que requer ação imediata, estão os itens 1, 8, 9 e 13, e na área que demanda atenção, 3, 4, 5, 10 e 12. Ficaram na área de baixo risco apenas os itens 2, 6, 7 e 11 .

Entre as mulheres não foi encontrado nenhum item na área de alto risco (ação imediata) e na de médio risco (atenção). Os itens 1, 2, 3, 5, 8, 13 e os demais estão na área de baixo risco, sugerindo que as mulheres são mais cuidadosas no que se refere a atos de segurança sanitária.

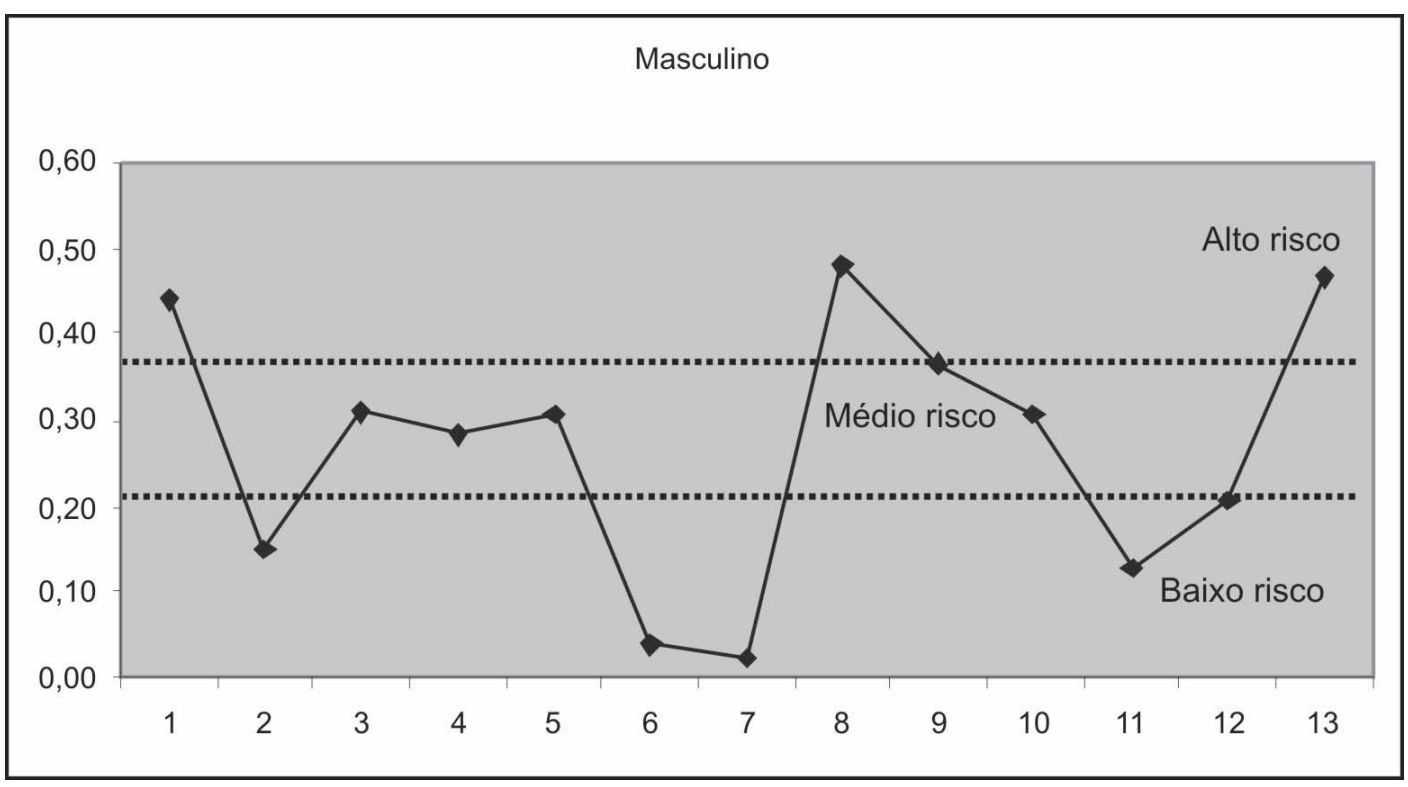

Figura 1. Carta de controle de práticas de risco no sexo masculino

Legenda: 1. Não higienizar as mãos imediatamente antes do autosserviço; 2. Mexer no cabelo perto das preparações expostas no balcão; 3. Falar em cima das preparações no balcão de distribuição; 4. Deixar a gravata, a manga de camisas, bolsas, blusas, vestidos ou casacos tocarem nas preparações; 5. Deixar parte do corpo encostar nas preparações; 6. Tossir sobre as preparações; 7. Espirrar sobre preparações; 8. Utilizar o utensílio de uma preparação em outra já servida no prato do consumidor; 9. Trocar os utensílios das preparações; 10. Deixar o utensílio cair dentro da preparação; 11. Retirar alimentos do seu prato e devolvê-los às cubas com a mão ou utensílio disponível; 12. Consumir alimentos antes da pesagem; 13. Arrumar alimentos no prato com os utensílios das preparações. 


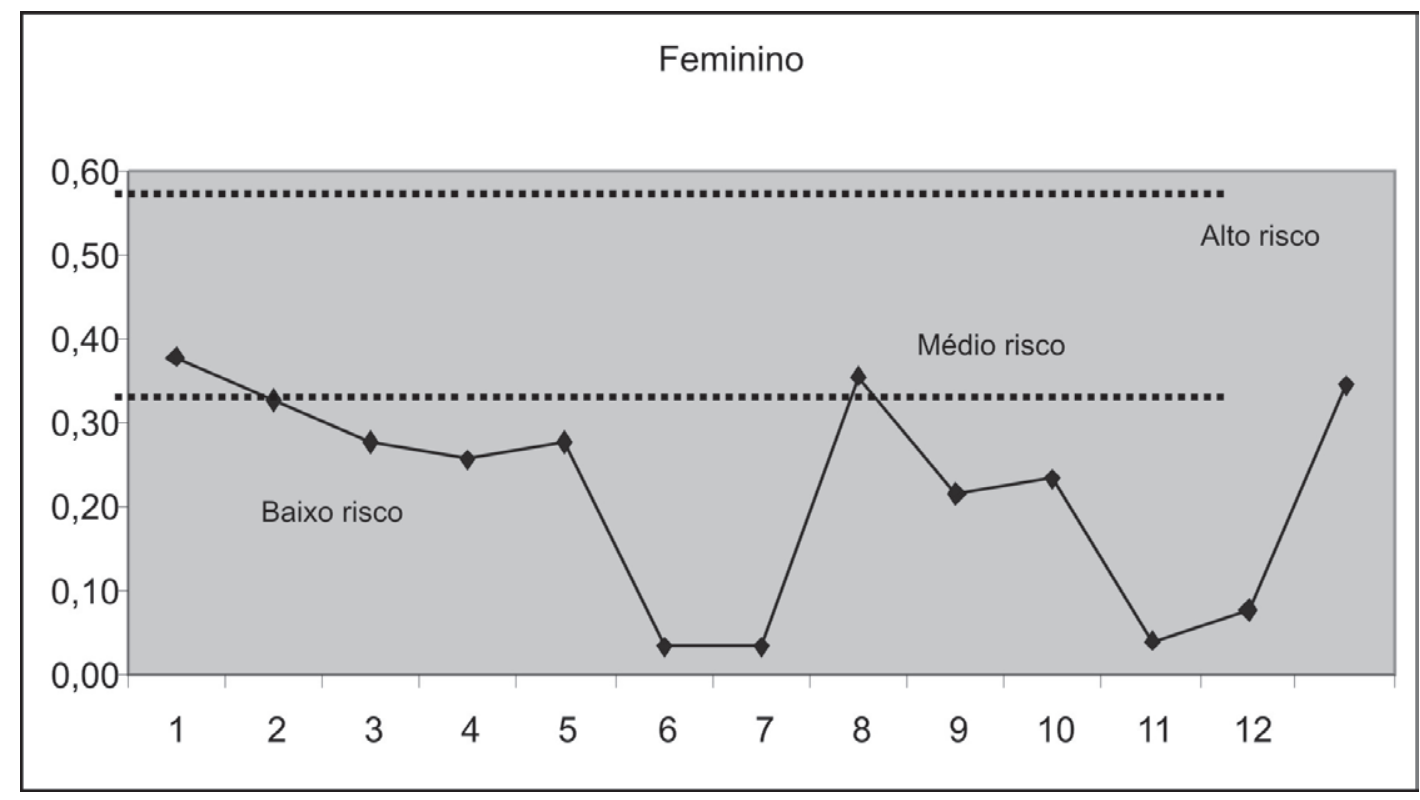

Figura 2: Carta de controle de práticas de risco no sexo feminino

Legenda: 1. Não higienizar as mãos imediatamente antes do autosserviço; 2. Mexer no cabelo perto das preparações expostas no balcão; 3. Falar em cima das preparações no balcão de distribuição; 4. Deixar a gravata, a manga de camisas, bolsas, blusas, vestidos ou casacos tocarem nas preparações; 5. Deixar parte do corpo encostar nas preparações; 6. Tossir sobre as preparações; 7. Espirrar sobre preparações; 8. Utilizar o utensílio de uma preparação em outra já servida no prato do consumidor; 9. Trocar os utensílios das preparações; 10. Deixar o utensílio cair dentro da preparação; 11. Retirar alimentos do seu prato e devolvê-los às cubas com a mão ou utensílio disponível; 12. Consumir alimentos antes da pesagem; 13. Arrumar alimentos no prato com os utensílios das preparações.

A figura 3 confirma os perfis anteriormente estudados. Na comparação da prática de risco por sexo com aquela identificada pelo total de usuários verifica-se que os homens $(\mathrm{n}=90)$ estão liderando práticas de risco na maioria dos itens a exceção de 2 e 7 . O teste qui quadrado demonstrou diferença significativa (qui-quadrado $=13.75,1 ; \mathrm{p}<0,002$ ) entre sexos. 


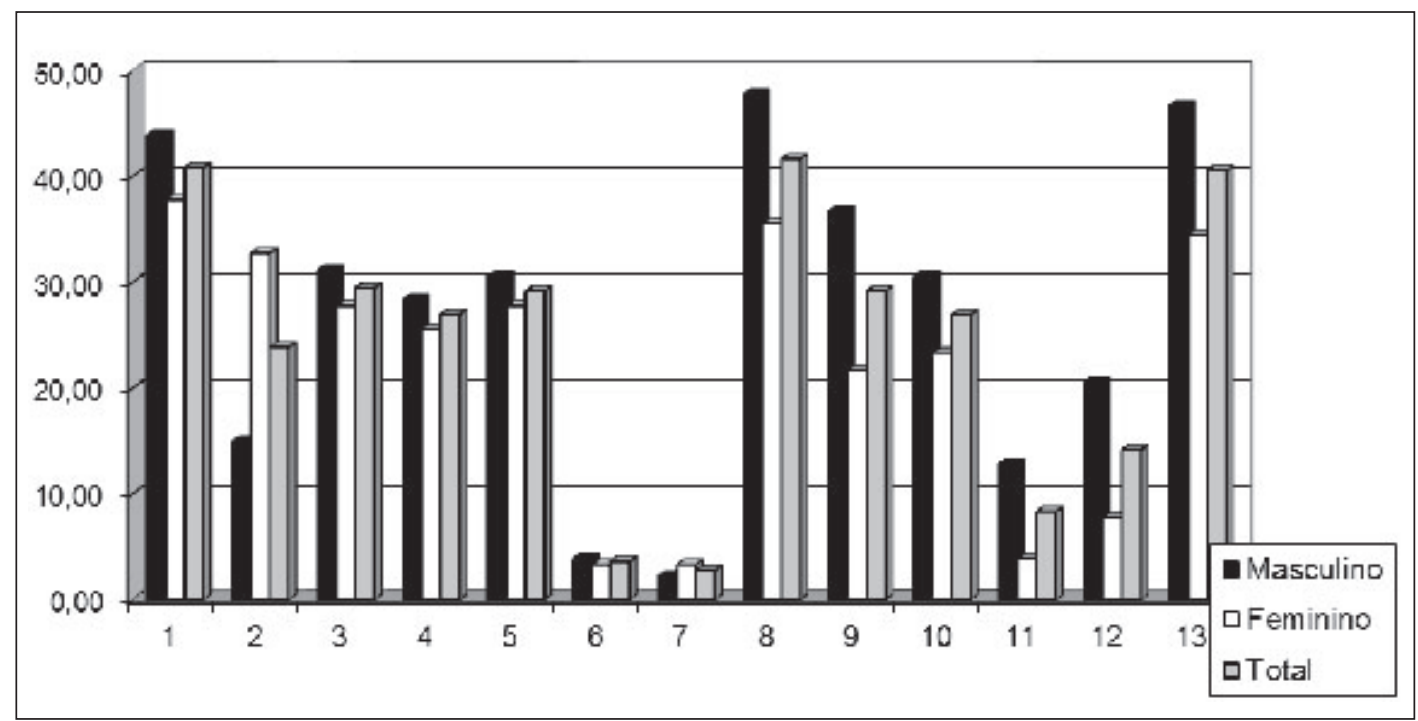

Figura 3. Comparação entre os percentuais de usuários com práticas de risco segundo sexo e total

Legenda: 1. Não higienizar as mãos imediatamente antes do autosserviço; 2. Mexer no cabelo perto das preparações expostas no balcão; 3. Falar em cima das preparações no balcão de distribuição; 4. Deixar a gravata, a manga de camisas, bolsas, blusas, vestidos ou casacos tocarem nas preparações; 5 . Deixar parte do corpo encostar nas preparações; 6. Tossir sobre as preparações; 7. Espirrar sobre preparações; 8. Utilizar o utensílio de uma preparação em outra já servida no prato do consumidor; 9. Trocar os utensílios das preparações; 10. Deixar o utensílio cair dentro da preparação; 11. Retirar alimentos do seu prato e devolvê-los às cubas com a mão ou utensílio disponível; 12. Consumir alimentos antes da pesagem; 13. Arrumar alimentos no prato com os utensílios das preparações.

\section{Discussão}

A falta de higienização das mãos dos manipuladores de alimentos ou dos próprios clientes, no caso dos self-service, possibilita a contaminação alimentar, levando ao risco de toxinfecções. ${ }^{21}$ Analisando-se homens e mulheres, foram encontrados $40 \%$ dos usuários com práticas de risco, pois não realizaram a higienização das mãos antes de utilizar o autosserviço.

Banczek et al., ${ }^{21}$ utilizando o instrumento proposto por Zandonadi et al. ${ }^{14}$ em dois restaurantes classe A (preço da refeição maior que $\mathrm{R} \$ 20,00)$, verificaram que os clientes não tinham o hábito de lavar as mãos antes do autosserviço. Nos dois estabelecimentos, os autores registraram que $82 \%$ e $97 \%$ dos usuários procediam desse modo. Estes achados se referem a práticas culturais arraigadas na população, demandando ações de intervenção junto à clientela, além daquelas habitualmente dirigidas aos manipuladores de alimentos.

De acordo com Zandonadi et al., ${ }^{14}$ a contaminação alimentar pode ocorrer por meio de práticas como mexer nos cabelos 
(7\%) perto das preparações, seja pelo contato direto do cabelo que cai sobre a preparação, seja por sua transmissão ao ambiente. Assim como tossir, cantar ou falar sobre os alimentos $(53,4 \%)$, além da roupa, as partes do corpo e os demais objetos (14\%) são igualmente veiculadores de microrganismos aos alimentos. Neste estudo, foram encontrados 29,4\% dos usuários falando no momento de se servir, $26,9 \%$ deixando parte de suas vestimentas sobre as preparações alimentares e ainda 29,1\% tocaram com seu corpo os alimentos. Banczek et al. (2010) também observaram percentuais bem mais elevados, no item "falar em cima das preparações", em dois restaurantes classe A $(69 \%$ e $61 \%)$. No presente estudo, embora apenas $5 \%$ tenham tossido ou espirrado perto das preparações, esta é uma prática considerada de alto risco.

No estudo de Zandonadi et al., ${ }^{14}$ foi encontrado que 23,8\% dos usuários mexiam no cabelo no ato de compor seu prato e não foi diferente no estudo de Banczek et al., ${ }^{21}$ quando identificaram a mesma prática em dois restaurantes classe A (15\% e 30\%).

Neste estudo, no que se refere ao manuseio dos utensílios no autosserviço, foi verificado que 40,5\% dos usuários arrumaram os alimentos no seu prato com os utensílios de servir e 29,1\% trocaram os utensílios das preparações, o que é mais uma prática que compromete a segurança do alimento. Além disso, 26,9\% dos usuários deixaram o utensílio cair dentro da preparação e percentual menor $(8,33 \%)$ retirou alimentos do seu prato e os devolveram às cubas com a mão ou utensílio. Banczek et al. ${ }^{21}$ identificaram, em dois restaurantes, que $20,51 \%$ e $10,25 \%$ dos usuários arrumavam os alimentos no prato com os utensílios de servir. Zandonadi et al. ${ }^{14}$ identificaram que $50 \%$ dos usuários trocavam os utensílios das preparações. O hábito de "beliscar", consumir os alimentos antes da pesagem, parece ser costumeiro entre usuários de serviço self service. O estudo identificou quase $15 \%$ dos usuários com esta prática, enquanto Zandonadi et al. ${ }^{14}$ e Banczek et al. ${ }^{21}$ registraram valores correspondentes a $3 \% \mathrm{e}$ $2,56 \%$, respectivamente.

As cartas de controle da prática de risco (figura 1 e 2) apresentam perfis diferentes para homens e mulheres, indicando que estas parecem ser mais cuidadosas do que os homens, uma vez que apresentam maior número de itens na área de baixo risco (6) em relação aos homens (4). Além disso, as mulheres não apresentaram nenhum item na área de alto risco, diferentemente dos homens, que apresentaram quatro itens.

Assim, entre os homens, as ações educativas deveriam focar predominantemente a higiene das mãos e o uso correto dos utensílios. No entanto, não se pode desprezar a atenção requerida nos itens alocados em médio risco, coincidindo para ambos os sexos nas seguintes práticas: "falar sobre as preparações" e "encostar parte do corpo nas mesmas".

Entre homens e mulheres, deve-se ainda evitar o contato das vestes com os alimentos, o hábito de manipular alimentos e utensílios e devolvê-los aos recipientes de atendimento das refeições. Especificamente entre as mulheres, 
embora se encontrem na área de médio risco, também não se identificou o hábito de higienizar as mãos antes de se servir, e também mexer no cabelo próximo as preparações, sendo necessária orientação para que tais práticas de risco não sejam realizadas.

Segundo Castiel, ${ }^{22}$ a Saúde Pública deve ser vista como um domínio genérico de práticas sociais em termos de ações e medidas que evitem, reduzam ou minimizem agravos à saúde. De acordo com as reflexões do autor, não se pode negar que, na sociedade hodierna, o processo de fragmentação da Saúde Pública em diferentes categorias vem dificultando a adoção de práticas sociais que poderiam incorporar conhecimentos básicos de higiene para uma vida necessariamente saudável.

As práticas higiênico-sanitárias observadas neste estudo fazem parte das cenas da sua vida. E a questão que se coloca é: como exigir dos manipuladores de alimentos e usuários as práticas higiênico-sanitárias adequadas, se estas não foram devidamente ensinadas nas escolas e não se tornaram rotineiras nos domicílios? Entre tantas possíveis respostas, talvez seja que as informações não foram transmitidas de forma que ganhassem significação e importância para a vida das pessoas - ou seja, foram ineficazes para a finalidade social a que destinam.

Particularmente nos países em desenvolvimento, estão retornando epidemias de antigas moléstias, entre elas as toxinfecções hemorrágicas intestinais por alimentos indevidamente processados em sistemas de cafeteria e fast food. Na verdade, essas ocorrências são bem mais comuns do que se imagina, uma vez que os surtos têm subnotificação. A questão da contaminação não é exclusiva dos manipuladores de alimentos, sendo também dos usuários, uma vez que estes podem ser transmissores de cepas de Escherchia coli. Assim, não é surpresa que as práticas de risco encontradas neste estudo e a intervenção, mesmo que pontual e não sistêmica, exigem treinamento para os manipuladores de alimentos, bem como a divulgação das normas higiênico-sanitárias para os usuários. Isto deve ser feito de forma que as mensagens tenham algum significado para eles e sejam transmitidas não só pela mídia escrita, falada e televisiva, mas na relação face a face, no cotidiano de crianças, adolescentes, adultos e até mesmo de idosos.

Os achados, tendo em vista sua relevância, indicam ser muito importante replicar o estudo em diferentes UPRs, segundo as categorias de atendimento no serviço.

\section{Conclusão}

Os usuários apresentam práticas de risco para a contaminação de alimentos no ato do atendimento de refeições, sendo que em algumas situações pesquisadas o risco é bem expressivo, sobretudo entre os homens 


\section{Referências}

1. Monteiro CA, Mondini L, Costa RBL. Mudanças na composição e adequação nutricional da dieta familiar nas áreas metropolitanas do Brasil (1988-1996). Rev. Saude Publica. 2000; 34(3): 251-58.

2. IBGE. Indicadores de desenvolvimento sustentável - Brasil 2008 [Acesso em 02 jul 2012]. Disponível em: ftp://geoftp.ibge.gov.br/ documentos/recursos_naturais/indicadores_ desenvolvimdese_sustentavel/ids2008.pdf

3. Brasil. Ministério da Saúde. Departamento de Atenção Básica. Política Nacional de Alimentação e Nutrição. Brasília: Ministério da Saúde; 2012. 84 p. (Série B. Textos Básicos de Saúde).

4. Badaró ACL. Boas práticas para um serviço de alimentação: um estudo para restaurantes comerciais do município de Ipatinga, Minas Gerais [Dissertação]. Universidade Federal de Viçosa: Viçosa; 2007. 156 f.

5. Akutsu RC, Botelho RA, Camargo E et al. Adequação das boas práticas de fabricação em serviços de alimentação. Rev. Nutr. 2005; 18(3): 419-27.

6. Departamento Intersindical de Estatística e Estudos Socioeconômicos. A mulher chefe de domicílio e a inserção feminina no mercado de trabalho. 2004 Mar 2004 [acesso em 2 jul 2012]: (n. ${ }^{\circ}$ esp.): Disponível em: http://www. sei.ba.gov.br/images/releases_mensais/pdf/ ped/ped_estudos_especiais/mulher_chefe.pdf

7. Associação brasileira das empresas de refeição coletiva [homepage na internet]. História e Mercado [acesso em 10 abr 2011]. Disponível em: http://www.aberc.com.br
8. Brasil. Ministério da Saúde. Secretaria de Vigilância Sanitária. Portaria no 326, de 30 de julho de 1997. Aprova o Regulamento Técnico sobre "Condições HigiênicoSanitárias e de Boas Práticas de Fabricação para Estabelecimentos Produtores/ Industrializadores de Alimentos”. Diário Oficial da União 1 ago 1997.

9. Agência Nacional de Vigilância Sanitária (Brasil). Resolução RDC no 275, de 21 de outubro de 2002. Dispõe sobre o Regulamento Técnico de Procedimentos Operacionais Padronizados aplicados aos Estabelecimentos Produtores/Industrializadores de Alimentos e a Lista de Verificação das Boas Práticas de Fabricação em Estabelecimentos Produtores/ Industrializadores de Alimentos. Diário Oficial da União 23 out 2003.

10. Agência Nacional de Vigilância Sanitária (Brasil). Resolução RDC no 216, de 15 de setembro de 2004. Dispõe sobre Regulamento Técnico de Boas Práticas para Serviços de Alimentação. Diário Oficial da União 16 set 2004.

11. Silva Junior EA. Manual de Controle HigiênicoSanitário em Serviços de Alimentação. São Paulo: Livraria Varela; 2005.

12. Brasil. Ministério do Desenvolvimento Social e Combate à Fome. Lei 11.346/2006. Cria o sistema Nacional de Segurança Alimentar e Nutricional - SISAN com vistas em assegurar o direito humano à alimentação adequada e dá outras providências. Diário Oficial da União 18 set 2006, p.1. [Acesso em 2 jul 2012] Disponível em: http://www.planalto.gov.br/ ccivil_03/_ato2004- 
13. Soares, MJ, Tokumaru-Miyazaki NH, Noleto AL, Figueiredo AM. Enterotoxin production by Staphylococcus aureus clones and detection of Brazilian epidemic M R S A clone (III::B:A) among isolates from food handlers. J Med Microbiol. 1997; 46(3): 214-21.

14. Zandonadi RP, Botelho RBA, Savio KEO, Akutsu RC, Araujo WMC. Atitudes de Risco do Consumidor em Restaurantes de autoserviço. Rev Nutr. 2007; 20(1): 19-26.

15. Brasil. Ministério da Saúde. Vigilância Epidemiológica das Doenças Transmitidas por Alimentos no Brasil, 1999 - 2010 [acesso em 2011 abr 10]. Disponível em: http://portal. saude.gov.br/portal/saude/profissional/ visualizar_texto.cfm?idtxt $=31758$

16. Selltz et al. Métodos de pesquisa nas relações sociais. São Paulo: Ed. Pedagógica e Universitária; 1974. p.687.

17. Rodrigues PC. Bioestatítica. Niterói, RJ: EdUFF; 2002.
18. Reichhenheim ME, Moraes CL. Qualidade dos instrumentos epidemiológicos. In: Epidemiologia: Fundamentos, Métodos e Aplicações. Rio de Janeiro: GuanabaraKogogan; 2011. p 31.

19. Streiner DL, Norman GR. Health Measurement Scales: A practical guide to their development and use. 2th ed. Oxford: Oxford Medical Publications, Inc.; 1995.

20. Motulsky HJ. Prism 4 Statistics Guide: Statistical analyses for laboratory and clinical researchers. Graph Pad Sofware Inc.: San Diego, CA; 2003.

21. Banczek HFL, Vaz CR, Monteiro AS. Comportamento dos consumidores em self service no município de Curitiba. RBTA. 2010; 4(1): 29-41.

22. Castiel DL. Uma Saúde Pública Molecular. Cad Saúde Publ. 1994; 10(3): 285-319.

Recebido: 06/3/2012

Aprovado: 30/7/2012 